Title:

Chemical-Vapor Deposition of Complex Oxides: Materials and Process Development

Author(s):

Submitted to:
Ross Muenchausen, MST-11

REOEVED

$$
\begin{aligned}
& \text { EOV } 149966 \\
& \text { OSTI }
\end{aligned}
$$

DOE Office of Scientific and Technical Information (OSTI)

\section{(OST)}

\section{Los Alamos}

NATIONAL LABORATORY 


\section{DISCLAIMER}

Portions of this document may be illegible in electronic image products. Images are produced from the best available original document. 


\section{DISCLAIMER}

This report was prepared as an account of work sponsored by an agency of the United States Government. Neither the United States Government nor any agency thereof, nor any of their employees, makes any warranty, express or implied, or assumes any legal liability or responsibility for the accuracy, completeness, or usefulness of any information, apparatus, product, or process disclosed, or represents that its use would not infringe privately owned rights. Reference herein to any specific commercial product, process, or service by trade name, trademark, manufacturer, or otherwise does not necessarily constitute or imply its endorsement, recommendation, or favoring by the United States Government or any agency thereof. The views and opinions of authors expressed herein do not necessarily state or reflect those of the United States Government or any agency thereof. 


\title{
Chemical-Vapor Deposition of Complex Oxides: Materials and Process Development
}

\author{
Ross Muenchausen*
}

\begin{abstract}
This is the final report of a six-month, Laboratory-Directed Research and Development (LDRD) project at the Los Alamos National Laboratory (LANL) part of the Advanced Materials Laboratory (AML). The demand for higher performance and lower cost in electronics is driving the need for advanced materials and consequent process integration. Ceramic thin-film technology is becoming more important in the manufacture of microelectronic devices, photovoltaics, optoelectronics, magneto-optics, sensors, microwave, and radio frequency communication devices, and high- $T_{c}$ superconducting tapes. A flexible processing approach for potential large-scale manufacturing of novel electronic ceramic thin films is desirable. Current thin-film deposition technologies based on physical vapor-deposition techniques are limited in scale potential and have limited control of processing parameters. The lack of control over multiple process parameters inhibits the versatility and reproducibility of the physical vapor deposition processes applied to complex oxides. Chemical vapor deposition is emerging as a viable approach for large-scale manufacturing of electronic materials. Specifically, the ability to control more processing parameters with chemical vapor deposition than with other processing techniques provides the reliability and material property reproducibility required by manufacturing. This project sought to investigate the chemical vapor deposition of complex oxides.
\end{abstract}

\section{Background and Research Objectives}

Electronic ceramics can be broadly classified as oxide and non-oxide materials. A general class of oxide ceramics is of the type $\mathrm{ABO}_{3}$, i.e., perovskites. The perovskites of interest to us are layered materials, generally of orthorhombic crystal structure, consisting of

* Principal investigator, e-mail: rossm @lanl.gov 
"electronically active" layers, separated by "insulating" layers. By varying the active layer composition and the coupling between the active layers, a wide variety of electronic properties are attainable in addition to the common electrically insulating behavior, which itself can be exploited to produce very high-dielectric-constant insulators (e.g., Ba-Sr-Ti-O). These properties include metallic conductivity ( $\mathrm{La}-\mathrm{Sr}-\mathrm{Co}-\mathrm{O})$, high-temperature superconductivity ( $\mathrm{Y}$ $\mathrm{Ba}-\mathrm{Cu}-\mathrm{O}$ ), ferroelectricity ( $\mathrm{Pb}-\mathrm{Zr}-\mathrm{Ti}-\mathrm{O})$, and magnetoresistivity ( $\mathrm{La}-\mathrm{Ca}-\mathrm{Mn}-\mathrm{O}$ ).

As the potential technological utility of these materials has emerged over the last decade, there has been increased interest in exploiting their unique electronic properties for microelectronic device applications. Chemical vapor deposition (CVD), which already is one of the most important methods for thin-film deposition in the electronics industry, has received increasing attention as a promising technique for deposition of these novel oxide materials. In particular, plasma-enhanced and plasma-assisted CVD have extended the technique to the low temperature processing (less than $500^{\circ} \mathrm{C}$ ) of electronic materials. The terms "plasmaenhanced" or "remote plasma-enhanced" are to be distinguished from the term "plasmaassisted," as the latter involves some ion bombardment of the growing film from the plasma, whereas the former uses the plasma solely to activate precursor fragments, thus adding nonthermal energy to the film growth process.

As might be expected, there has been a considerable effort in developing suitable CVD precursors for transition- and lanthanide-metal-oxide deposition. In favorable cases, single source precursors, which have multiple cations matching the desired film stoichiometry, have been synthesized, but volatility constraints generally limit their utility. A wide variety of single-metal-cation containing complexes have been synthesized. However, multiple source requirements impose restrictions on precursor compatibility, i.e., exchange reactions must be avoided, as well as precursor lability, which directly affects source stability and consequent film stoichiometry control. Another factor that is generally overlooked in research and development of precursors, but which will strongly impact on manufacturing, is the precursor cost, which can become prohibitive as precursor complexity increases.

These considerations have pushed development of new precursor delivery systems designed to reduce the constraints on precursor volatility and lability. One approach is to flash evaporate liquid precursors by injection onto a warm surface (this is called liquid-source delivery), though the same approach has been demonstrated for solid precursors as well. While this delivery system overcomes thermal lability constraints, the precursor delivery rate into the reactor is still limited by vapor pressure considerations. Chemical reactions can occur over time on the source plate to give a metal film that can further catalyze precursor decomposition. This approach, like conventional bubbler sources, also requires heat-traced lines into the reactor. 
Another approach, which overcomes some of the limitations of liquid-source delivery, uses aerosol generation and evaporation as the delivery mechanism of the precursor. Aerosolassisted CVD injects a fine mist of liquid droplets into a heated zone to vaporize precursors. Solid precursors dissolved in a suitable solvent can also be utilized for this technique. Since the aerosol generator generally operates near atmospheric pressure, so that the droplets evaporate before settling in the reactor, this delivery system is well suited for feeding a highpressure plasma. This process is frequently referred to in the literature as plasma vapor deposition. Plasma spraying, on the other hand, deposits the liquid or partially melted solid directly onto the substrate.

A significant advantage of the plasma-vapor-deposition process is that, like plasma spraying and tape casting, it is a non-vacuum process amenable to large-scale production. However, the high gas pressures and temperatures may result in films of degraded properties due to loss of surface-chemistry-driven selectivity and conformality as well as lower deposition rates. This limitation however, is not important for many thick film applications. In those cases, there is no advantage to using CVD precursors.

\section{Importance to LANL's Science and Technology Base and National R\&D Needs}

This project supports a Los Alamos core competency in nuclear and advanced materials. An aerosol source delivery system, amenable to commercial plasma-vapor-deposition processing of perovskite thick films, would have a direct impact on using $\quad \mathrm{Pb}_{\mathrm{x}} \mathrm{Zr}_{1-\mathrm{x}} \mathrm{TiO}_{3}$ (PZT) ferroelectric capacitors. Even for applications outside of microelectronics, such as the revolutionary thick-film-tape conductor developed by our own Superconductivity Technology Center, development of a manufacturable thick-film process for the $\mathrm{Y}-\mathrm{Ba}-\mathrm{Cu}-\mathrm{O}$ layer would greatly aid commercialization efforts.

\section{Scientific Approach and Results to Date}

The project investigated CVD approaches to commercial-scale manufacture of decoupling capacitors and thin-film RC networks currently manufactured by AVX Corporation. Conventional tape casting cannot consistently produce films below 4-micron thickness. Optimized sol-gel processing has difficulty producing films greater than 1-micron thick. We first investigated the efficacy of CVD for 2-micron-thick film production. The prime consideration was cost. The need for vacuum processing and organometallic precursors for a high-throughput, relatively thick-film process for CVD did not make it cost competitive. 
We investigated alternatives to CVD. The most promising that was identified was aerosol source plasma vapor deposition. It does not require high vacuum and can use much cheaper water soluble salts or oxalates or citrates. Since only polycrystalline films are required for the application of interest, the careful control of the surface-chemistry-regulated film growth in a CVD process is not required. An aerosol-assisted chemical vapor deposition (AACVD) reactor was designed and constructed. A radio-frequency plasma torch was designed for the existing AACVD reactor. A statistical experimental design was prepared to execute a parametric study of PZT thick film deposition. 